\title{
Adaptive Stem and Adventitious Root Responses of Two Tomato Genotypes to Flooding
}

\author{
Steven T. McNamara ${ }^{1}$ and Cary A. Mitchell ${ }^{2}$ \\ Center for Plant Environmental Stress Physiology, Department of \\ Horticulture, Purdue University, West Lafayette, IN 47907 \\ Additional index words. Lycopersicon esculentum, Lycopersicon peruvianum, \\ 1-aminocyclopropane-1-carboxylic acid, ethylene, root porosity
}

\begin{abstract}
Tomato accessions PI 128644 (Lycopersicon peruvianum var. dentatum Mill.) and PI 406966 (Lycopersicon esculentum Mill.) were identified in preliminary screening trials as being relatively nonresistant and resistant to $120 \mathrm{hr}$ of flooding, respectively. Many adventitious roots (AR) developed on the lower stems of flooded PI 406966 seedlings, while few formed on flooded PI 128644 plants. Root formation by flooded PI 406966 seedlings depended on de novo initiation rather than emergence of preformed initials. Hypocotyl porosity of PI 406966 plants increased from between $3 \%$ and $6 \%$ to $8 \%$ by 36 and $72 \mathrm{hr}$ of flooding, respectively. Porosity of PI 128644 hypocotyls was unchanged by $72 \mathrm{hr}$ of inundation. Flooding did not affect the secondary root porosity of either accession. The limited capacity of PI 128644 seedlings to develop AR and aerenchyma was not related to an inability to synthesize 1-aminocyclopropane-l.carboxylic acid or ethylene in response to hypoxia. Chemical name used: 1-aminocyclopropane-1-carboxylic acid (ACC).
\end{abstract}

Adventitious roots (AR) and aerenchyma tissue (AT) are important components in the adaptation of many plant species to flooding (Kawase, 1981). Tomato genotypes identified as possessing some degree of flood resistance generally were found to produce more AR during flooding than did less-resistant genotypes (Kuo and Chen, 1980; Lopez and del Rosario, 1983). Well-developed root AT also was associated with greater flood resistance. Aerenchyma were initiated within 24 $\mathrm{hr}$ of inundation and ultimately accounted for nearly $8 \%$ of total tissue volume (Kawase and Whitmoyer, 1980; Yu et al., 1969). Despite the apparent importance of AR and AT to plant survival during flood stress, factors governing genotypic capacity for such morphological adaptations are poorly understood.

Development of adaptative responses to flooding may be regulated by changes in hormone balance, including levels of endogenous ethylene $\left(\mathrm{C}_{2} \mathrm{H}_{4}\right)$. Flood-induced increases in $\mathrm{C}_{2} \mathrm{H}_{4}$ level occur in shoots of many species as a result of anaerobic stimulation of 1-aminocyclopropane-1-carboxylic acid (ACC) biosynthesis in roots (Bradford and

Received for publication 4 Apr. 1988. Purdue Univ. Agricultural Experiment Station Journal no. 11,367. We acknowledge the contribution of P. Allen Hammer, ASHS Associate Editor for statistics, for advisement and assistance in statistical analysis and graphic presentation of data. The cost of publishing this paper was defrayed in part by the payment of page charges. Under postal regulations, this paper therefore must be hereby marked $a d$ vertisement solely to indicate this fact.

'Present address: Univ. of Minnesota Landscape Arboretum, 3675 Arboretum Drive, Chanhassen, MN 55317.

${ }^{2}$ To whom reprint requests should be addressed.
'Yang, 1980).. Many morphological responses typically associated with flood stress, including AR and AT formation, can be induced under well-aerated conditions by exogenous $\mathrm{C}_{2} \mathrm{H}_{4}$ at physiologically active concentrations (Jackson et al., 1981).

Preliminary studies with tomato in our laboratoty have identified Lycopersicon peruvianum var. dentatum PI 128644 and Lycopersicon esculentum PI 406966 (USDA Plant Introduction Station, Ames, Iowa) as being relatively nonresistant and resistant to $120 \mathrm{hr}$ of flooding, respectively. Examination of these accessions indicated that PI 128644 possessed limited capacity for AT and AR development in response to inundation relative to that of PI 406966. The objectives of this study were to: 1) quantify AR and AT development in PI 128644 and PI 406966 during flooding, 2) determine whether preformed root initials contribute to floodinduced AR formation in PI 406966, and 3) determine whether the lack of adaptive response by PI 128644 might be accounted for by inability to synthesize ACC and/or $\mathrm{C}_{2} \mathrm{H}_{4}$. during root-zone inundation.

Seeds of PI 128644 and PI 406966 were sown in 10 -cm-diameter (0.8-liter) plastic pots containing coarse white silica sand (Weldron) and placed in a growth chamber. Environmental conditions, watering regime, and imposition of flood treatment were as described by McNamara and Mitchell (1989).

Flood treatment was imposed by placing each seedling pot into a 1.2-liter container filled with single-strength Hoagland's No. 1 nutrient solution. Plants were immersed to 1 $\mathrm{cm}$ above the sand surface. Control plants were placed within similar containers containing bottom-drainage holes, and were watered to field capacity once daily. Flood solution was changed midway through the 120-hr treatment period.

Capacity for AR formation in response to flooding was evaluated by counting the number of roots emerging through the epidermis of the hypocotyl and first internode after 120 hr of treatment.

The ACC content of secondary roots and $\mathrm{C}_{2} \mathrm{H}_{4}$ evolution rate from excised hypocotyls were measured at 24-hr intervals over 120 hr. Lyophilized root tissue was assayed for ACC content by the method of Lizada and Yang (1979). Hypocotyl sections were excised, weighed, placed in 5-ml reaction vessels (Supelco, Bellefonte, Pa.), and capped tightly with septum-sealed screw caps. After $1 \mathrm{hr}$, a 1.0-ml gas sample was withdrawn from each vial and analyzed for $\mathrm{C}_{2} \mathrm{H}_{4}$ content. Ethylene was measured with a gas chromatography (Varian Model 3300) equipped with a flame-ionization detector and a $2-\mathrm{mm}$ (id.), 182-cm-long column packed with activated alumina. Chromatograph oven temperatures were: injector $120 \mathrm{C}$, column $80 \mathrm{C}$, and detector $150 \mathrm{C}$. Flow rate of the $\mathrm{N}_{2}$ carrier gas was $40 \mathrm{ml} \cdot \mathrm{min}$

For histological studies, hypocotyls were fixed in formalin : glacial acetic acid : $95 \%$ ethanol (5:5:90, by volume), passed through an ethanol-tertiary butanol dehydration series, and embedded in Paraplast (Sass, 1958). Sections, $10 \mu \mathrm{m}$ thick, were stained with safranin/fast green.

The internal porosity of secondary root and hypocotyl tissues was measured using a pycnometer method (Jensen et al., 1969).

Data were subjected to analysis of variance and regression procedures.

No AR developed on lower stems (hypocotyl and first internode) of nonflooded PI 406966 or PI 128644 seedlings. Flooding for
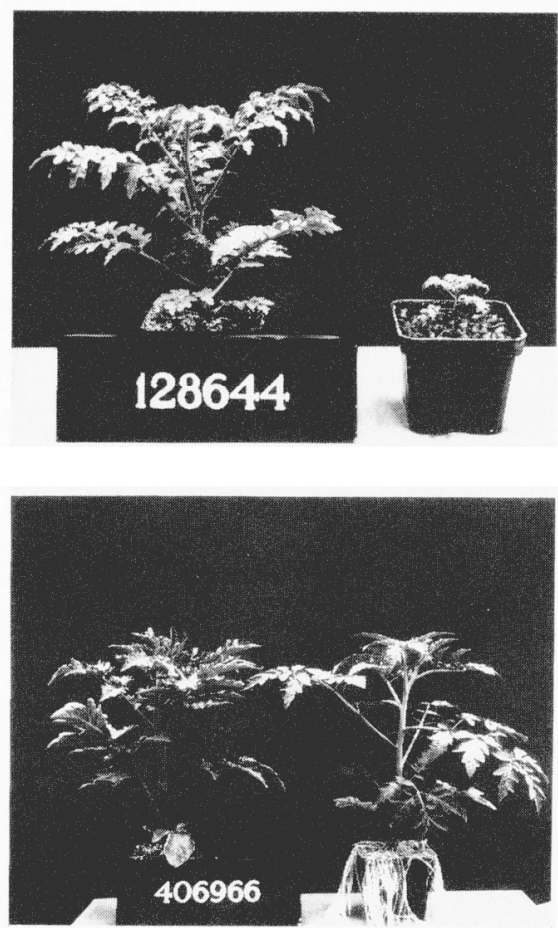

Fig. 1. Nonflooded (left of each pair) and flooded (right of each pair) PI 128644 and PI 406966 tomato seedlings after 16 days of treatment. 

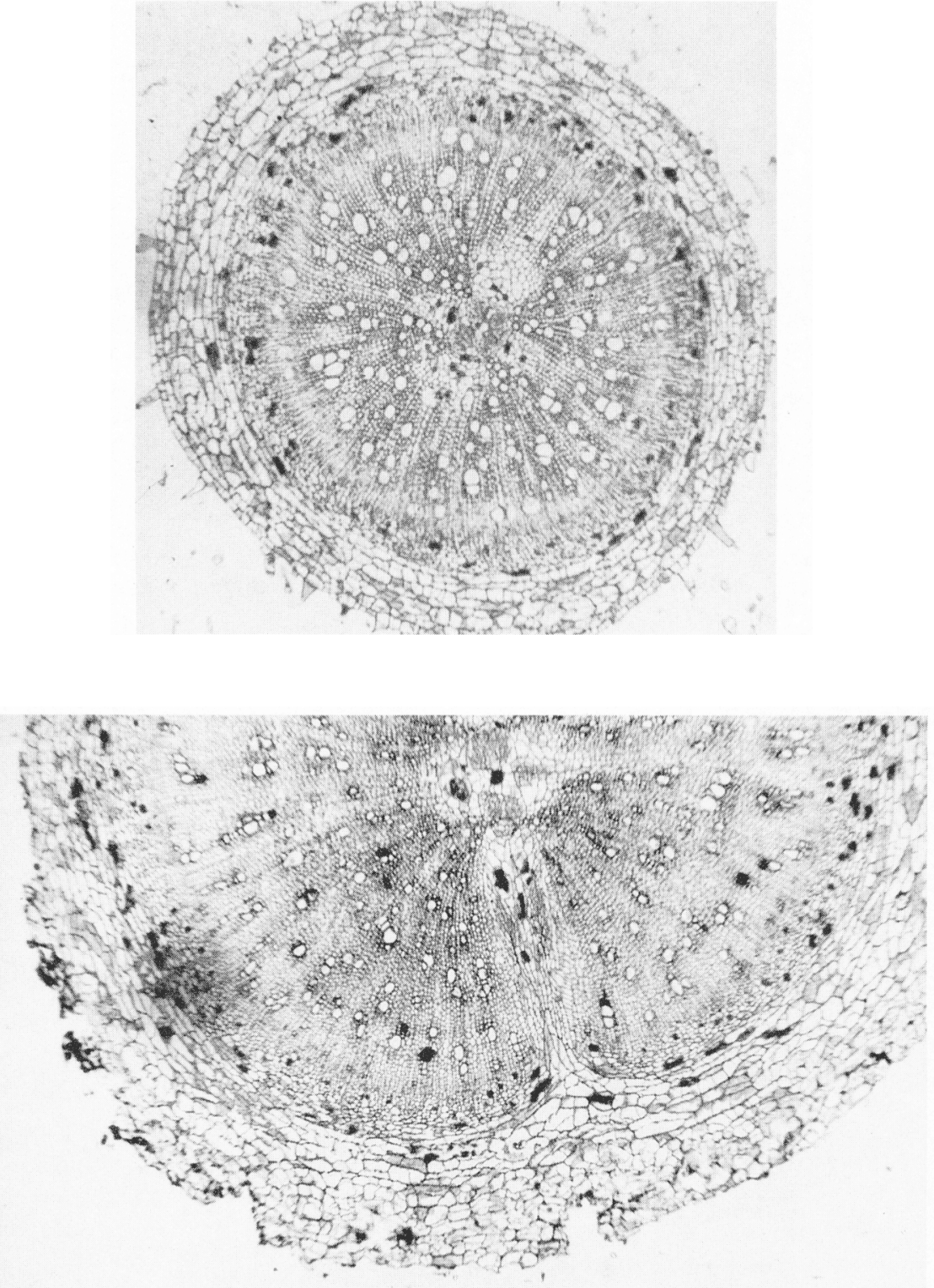

Fig. 2. Hypocotyl cross-sections of PI 128644 tomato seedlings flooded for 0 (top) or $120 \mathrm{hr}$ (bottom), showing absence of adventitious root primordia. Magnification $=\times 8$ (top), $\times 25$ (bottom).

$120 \mathrm{hr}$ significantly increased the number of AR on PI 406966 (133 per plant), but not on PI 128644 (four per plant). Differences in AR-forming capacity became even more pronounced when the flood period extended beyond $120 \mathrm{hr}$ (Fig. 1).

Adventitious root formation by flooded tomato plants generally is believed to involve stimulation of preformed root initials (Jackson, 1985). We therefore speculated that the disparity in AR, formation between the two accessions might be related to difference in number of preformed root intials present before stress. However, microscopic examination of thin sections of hypocotyl tissue revealed no preformed root initials in the hypocotyls of either tomato species before flooding. Furthermore, no initials developed in PI 128644 plants flooded for up to $120 \mathrm{hr}$ (Fig. 2). However, root initials were first visible in sections of PI 406966 hypocotyls
$=0.05)$ revealed that secondary roots of PI 406966 normally were slightly more porous than those of PI 128644 (1.9\% vs. 1.3\%).

$\mathrm{T}$ he greater porosity of flooded PI 406966 hypocotyls may facilitate both the entry of $\mathrm{O}_{2}$ from the aerial environment as well as its subsequent transport to submerged tissues. Lack of flood-induced enhancement of root porosity may indicate that secondary roots of both accessions are poorly adapted for internal aeration under waterlogged conditions. Alternatively, the pycnometer method used may not have been sensitive enough to determine very small porosity changes (Luxmoore and Stolzy, 1969). Previous studies with tomato were reported to increase porosity of secondary roots during flooding (Lopez and del Rosario, 1983; Yu et al., 1969). Flooded secondary roots of PI 406966 typically appeared healthier than those of PI 128644.

Luxmoore and Stolzy (1969) found the porosity of AR newly formed by flooded Oryza sativa and Zea mays seedlings to be substantially greater than that of flooded secondary roots on the same plant. Lopez and del Rosario (1983) reported that aerobic respiration rates were much higher for $A R$ than for secondary roots of flooded tomato. Adventitious roots of PI 406966 had greater internal porosity than did flooded or nonflooded secondary roots; they also sustained the highest capacity for aerobic respiration (data not presented), suggesting they were wellsupplied with $\mathrm{O}_{2}$ (Vartapetian et al., 1978). The major adaptive value of increased hypocotyl porosity in flooded PI 406966, therefore, may be to supply AR with $\mathrm{O}_{2}$.

Flood-induced changes in $\mathrm{C}_{2} \mathrm{H}_{4}$ metabolism have been implicated in regulating adaptive responses to flooding. Blake and Reid (1981) attributed the superior flood tolerance of Eucalyptus camaldulensis relative to other Eucalyptus spp. to its greater capacity for $\mathrm{C}_{2} \mathrm{H}_{4}$ production during waterlogging. They proposed that the higher levels of $\mathrm{C}_{2} \mathrm{H}_{4}$ produced by this species led to extensive stem hypertrophy, AT development, and, consequently, improved internal aeration.

The ACC content of secondary roots of PI 128644 and PI 406966 was affected similarly by flooding over time. Data, therefore, were combined over accession (Fig. 5, top). Content of ACC increased significantly with 24 $\mathrm{hr}$ of flooding and remained greater than control level throughout the treatment.

Ethylene evolution was similar for control plants of PI 128644 and PI 406966 (Fig. 5, bottom). Flooding affected the rate of $\mathrm{C}_{2} \mathrm{H}_{4}$ evolution from hypocotyl sections of the two accessions differently over time. Ethylene evolution from hypocotyls of both accessions had begun to increase by $24 \mathrm{hr}$ of flooding. However, hypocotyls of flooded PI 128644 plants produced significantly more $\mathrm{C}_{2} \mathrm{H}_{4}$ than did those of flooded PI 406966 plants over the entire treatment period. These results indicate that the restricted capacity of PI 128644 for AR and AT development is not limited by its ability to synthesize ACC or $\mathrm{C}_{2} \mathrm{H}_{4}$ during inundation. These findings 

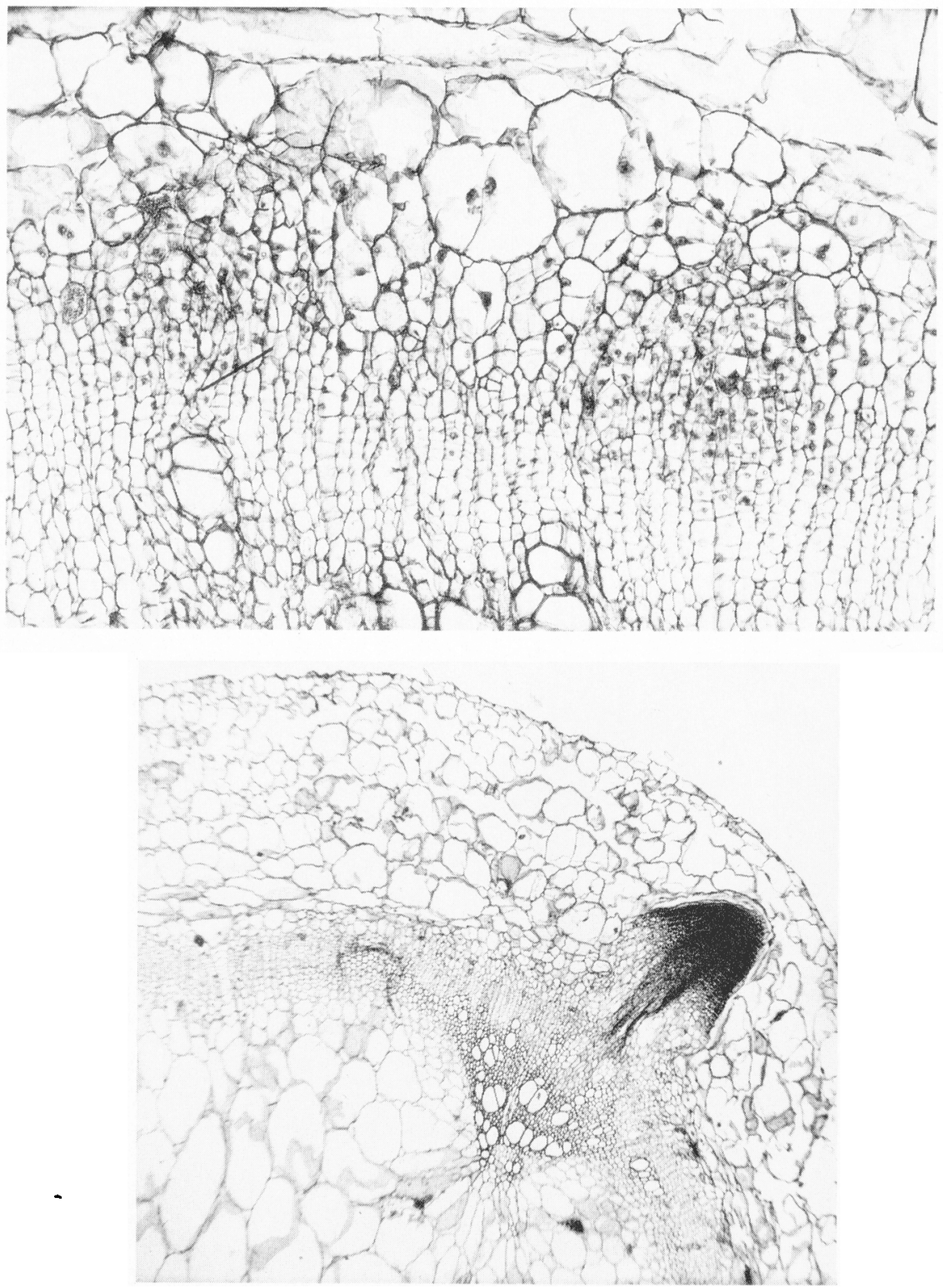

Fig. 3. Hypocotyl cross-sections of PI 406966 tomato seedlings flooded for 48 (top) or 96 hr (bottom), showing root initials and well-developed root primordia, respectively. Magnification $=\times 25$ (top), $\times 8$ (bottom).

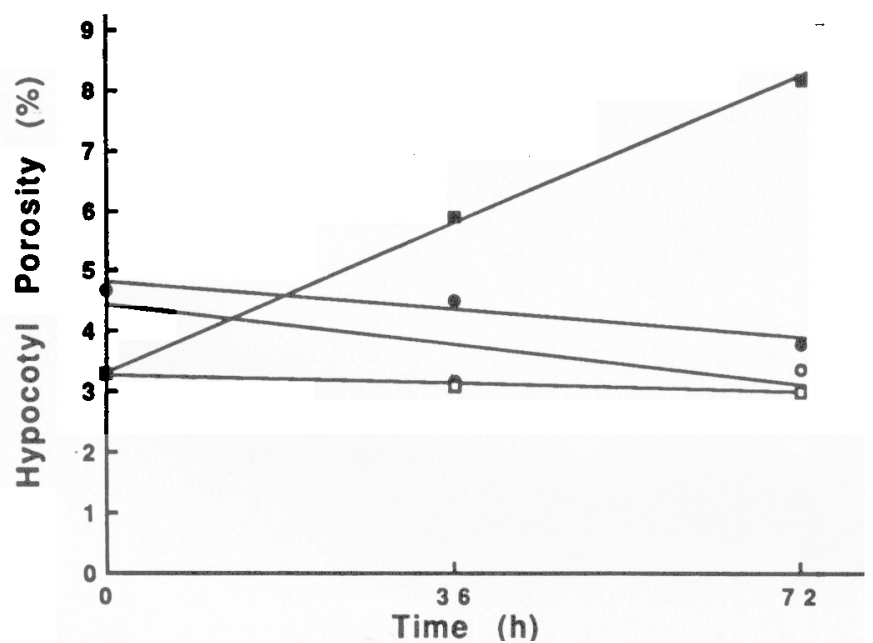

Fig. 4. Hypocotyl porosity of flooded and nonflooded tornado seedlings PI 128644 and PI 406966 during $72 \mathrm{hr}$ of treatment. Each data point represents the mean of measurements for six plants. $\mathrm{O}=$ Control of PI 128644: Y $=4.42-0.018 X, R^{2}=0.20 ; \quad=$ flood of PI 128644: $\mathrm{Y}=4.80$ $0.012 \mathrm{X}, R^{2}=0.12 ; \square=$ control of PI 406966: Y $=3.26-0.0037 \mathrm{X}, R^{2}=0.04 ; \boldsymbol{\square}=$ flood of PI 406966: $\mathrm{Y}=3.30+0.069 \mathrm{X}, R^{2}=0.69$. are further supported by our observation that application of $50 \mu \mathrm{l}$ of ethephon/liter as a soil drench failed to stimulate AR development in nonflooded PI 128644 (data not presented).

The sensitivity of PI 128644 to long-term root-zone inundation r-nay be a direct consequence of its inability to initiate development of adaptive responses such as AT and AR. Factors underlying the greater capacity of PI 406966 for AR and AT adaptations during flood stress still are unknown. Neither differences in capacity to produce stress $\mathrm{C}_{2} \mathrm{H}_{4}$ nor number of preformed root initials appear to be involved. Internal tissue anatomy of PI 128644 and PI 406966 hypocotyls differs considerably. Cortical and stelar tissues of PI 128644 hypocotyls consist of small, tightly arranged cells. Little intercellular space was visible. Signification of stelar tissue was suggested for PI 128644 by intensity of safranin staining (Sass, 1958). For PI 406966, cortex and stele were characterized by large, loosely arranged parenchyma cells with little evidence of signification. The greater size and looser arrangement of cortical parenchyma cells of PI 406966 might enhance responsiveness to $\mathrm{C}_{2} \mathrm{H}_{4}$ or other factors involved in AT development. Structural characteristics also could conceivably affect position and number of AR formed or the time required for their emergence. However, the complete absence of AR initials in PI 128644 suggests that additional differences of a more fundamental nature exist between resistant and nonresistant accessions.

\section{Literature Cited}

Blake, T.J. and D.M. Reid. 1981. Ethylene, water relations, and tolerance of three Eucalyptus species. Austral. J. Plant Physiol. 8:497-505.

Bradford, K.J. and S.F. Yang. 1980. Xylem transport of 1-aminocyclopropane-1-carboxylic acid, an ethylene precursor, in waterlogged tomato plants. Plant Physiol. 65:322-326.

Jackson, M.B. 1985. Ethylene and responses of plants to soil waterlogging and submergence. Annu. Rev. Plant Physiol. 36:145-174.

Jacksorr, M. B., M.C. Drew, and S.C. Giffard. 1981. Effects of applying ethylene to the root system of Zea mays on growth and nutrient concentration in relation to flooding tolerance. Physiol. Plant. 52:23-28

Jensen, C. R., R.J. Luxmoore, S.D. Van Gundy, and L.H. Stolzy. 1969. Root air space measurements by a pycnometer method. Agron. J. 61:474-475.

Kawase, M. 1981. Anatomical and morphological adaptations of plants to waterlogging. HortScience 16(1):8-12.

Kawase, M. and R.E. Whitmoyer. 1980. Aerenchyma development in waterlogged plants. Amer. J. Bet. 67(1): 18-22.

Kuo, C.G. and B.W. Chen. 1980. Physiological responses of tomato cultivars to flooding. J. Amer. Soc. Hort. Sci. 105(5):751-755.

Lizada, M.C.C. and S.F. Yang. 1979. A simple and sensitive assay for 1-aminocyclopropane-1carboxylic acid. Anal. Biochem. 100:140-145.

Lopez, M.V. and D.A. del Rosario. 1983. Performance of tomatoes [Lycopersicon lycopersicum (L.) Karsten] under waterlogged condition. Philippine J. Crop Sci. 8(2):75-80.

Luxmoore, R.J. and L.H. Stokzy. 1969. Root porosity and growth responses of rice and maize 